\title{
OMAE2019-96282
}

\section{DRAFT: ANALYSIS OF THE COUPLED DYNAMICS OF AN OFFSHORE FLOATING MULTI-PURPOSE PLATFORM, PART B: HYDRO-ELASTIC ANALYSIS WITH FLEXIBLE SUPPORT PLATFORM}

\author{
C. Ruzzo, G. Failla, F. Arena \\ Natural Ocean Engineering \\ Laboratory (NOEL), \\ Mediterranea University of \\ Reggio Calabria, Reggio \\ Calabria, Italy
}

\author{
M. Collu, L. Li \\ Department of Naval \\ Architecture, Ocean and Marine \\ Engineering, University of \\ Strathclyde, Glasgow, UK
}

\author{
A. Mariotti \\ Fincosit s.r.l., Genova, Italy
}

\section{ABSTRACT}

A multi-purpose platform (MPP) is an offshore system designed to serve the purposes of more than one offshore industry. Indeed, over the past decades, a number of industries have expanded, or are expanding, from onshore to offshore locations (renewables, aquaculture, tourism, mineral extractions, etc), and the research on these type of platform is increasing. In the present work, a MPP able to accommodate wind turbines, wave energy converters, and aquaculture systems is considered. For an overview of the MPP platform considered and its research context, please refer to the EU H2020 project overview (OMAE 2019-96104). This work presents the second part (Part B) of the analyses of the dynamics of the floating support structure for this MPP, focusing on the hydro-elastic analysis, while its complementary rigid-body hydrodynamic analysis is presented in Part A (OMAE2019-96212).

The aim here is to assess if the support platform structural elasticity has a substantial impact on the dynamic response of the platform. A beam model and a 3D solid model of the support structure have been developed, and the inertial forces, hydrodynamic added mass forces, hydrostatic and mooring restoring forces have been considered in the hydro-elastic analyses performed. The results show that the dynamic response to the wave loads is not substantially influenced by the elasticity of the support structure, and that, at first approximation, a rigid-body approach is acceptable.

\section{INTRODUCTION}

One of the most relevant challenges in these years is to address the urgent need of increasing food and energy production to feed and support the growing world population.
Offshore development is one of the most interesting potential answers to this challenge, since many unexplored possibilities may be investigated and realized in the future for food as well as energy production [1-3]. In particular, Large and Very Large Floating Structures (LFS, VLFS) are a promising concept for multi-purpose installations and often regarded as a new frontier for massive offshore development, although many technical and social issues are to be established (for a review see e.g. Refs. [4-5]). In this context, the recently funded "The Blue Growth Farm" EC project (GA n. 774426) [6] proposes an innovative, low-cost, multi-purpose, large floating concrete platform, based on modularity and able to host offshore multiple renewable energy devices, as well as aquaculture plants.

The design of such a platform is a highly complex and multi-disciplinary task [7], involving many areas of research including, among the others, aquaculture, offshore and structural engineering, renewable energy production, automation and control, economic, ethical and social acceptance issues. This paper will deal with a very specific task within this context, which is the hydro-elastic characterization of the dynamic response of the platform to environmental loads. This issue plays a crucial role in the establishment of the platform concept, since aquaculture plants functionality and renewable energy production depends strongly on platform dynamics. This paper follows a previous one [8] (Part A), which assessed the rigid body dynamics of the platform under hydrodynamic loads. However, the hypothesis of rigid body motions made in Ref. [8] is potentially questioned by the overall dimensions of the platform, which are relatively large, and by the different frequency distributions of the loads, including those coming from waves and from the wind turbine, that may excite the flexible modes of the structure. 
To investigate the relative importance of the flexible modes on the overall structure response, as well as potential resonance sources (e.g. from wind turbine), a preliminary draft of the platform design is considered in this paper, and modal analysis is performed by means of two independent numerical models. The first one is a beam model implemented in ADINA [9], where the structural elements of the platform are represented by pertinent beam elements. The second one is a fully threedimensional model implemented in ANSYS [10]. In both models, hydrodynamic added mass descends from the calculations performed in Ref. [8] and a simplified mooring system is used to obtain the desired stiffness.

The first ten undamped modes of the structure, including rigid and flexible body motions, are estimated in terms of mode shapes, natural frequencies and mass participation factors. The results obtained from both models support the rigid body motion approach of Ref. [8] as a reasonable first approximation of the platform behaviour, exclude the occurrence of severe resonance phenomena, and provide a useful basis for future elaborations on the coupled aero-hydro-elastic behaviour of the platform.

\section{MULTI-PURPOSE PLATFORM}

\section{Main characteristics}

The floating platform considered in the present study and in Ref. [8] is a simplified draft of the full-scale configuration introduced in "The Blue Growth Farm" project and should not be taken as representative of its final design.

It is a rectangular-shaped floating structure, made up of 16 concrete modules, rigidly linked to each other (see Figures 1-3). Each module has an inverse-T-shaped section, which is modified in the fore-side of the platform, since it is equipped with a U-OWC wave energy converter [11] and a wind turbine (represented as a lumped mass in Figures 1-2). The aft-, starboard and port- sides caissons are reinforced with transversal concrete stiffeners, aimed to improve structural resistance and hydrodynamic added mass, without increasing the hydrostatic stiffness significantly, so as to keep the natural periods of heave, roll and pitch motions sufficiently high [8]. Finally, the aft-side has some discontinuities, aimed to enhance the water exchange and the interaction between the platform and ships and other vehicles.

The wave energy converter is based on the REWEC3 concept [11-12], adapted to the floating platform, while the wind turbine is based on the DTU-10MW offshore wind turbine [13]. Since both the systems are placed at the fore-side, the structure itself is slightly unbalanced, which has been corrected with opportune ballast placed at the fore- and aft-side of the platform, designed so as to align vertically the centres of buoyancy and gravity, and to achieve the desired draft. The ballast has been represented as a set of lumped masses in Figures 1-2. The structure hosts six fish cages, placed inside the protected internal pool, as well as all the ancillary systems needed for the functionality and automation of the integrated systems (control room, batteries, cranes, fish food and other payloads), all represented as a single point mass, concentrated at the centre of the working area.

The design process of the structure is reported in Ref. [8], where the main requirements in terms of aero-hydrodynamic properties of the structure and stability are also presented. Herein, the focus is on to the flexible behaviour of the structure, and in particular to the frequency and the participant mass factor of each rigid and flexible mode. The aim of the analysis is to assess the importance of the coupling between hydrodynamics and elasticity for the whole platform, thus providing also a preliminary assessment of the impact of the rigidity hypothesis assumed in Ref. [8].

Concerning the mooring system, a simplified model is assumed as in Ref. [8], i.e. a linear stiffness matrix, obtained so as natural periods of rigid horizontal motions are sufficiently high. Since the flexible model here considered takes also into account the stiffness distribution along the platform, a simple approach with eight mooring lines, acting as linear springs in the horizontal plane, is adopted. In particular, two springs depart from each corner of the structure bottom, one in $\mathrm{x}$ direction and the other in y-direction.

The main characteristics of the structure in terms of geometry are reported in Table 1 , while Table 2 reports the mass properties of the structure and the stiffness of each mooring line. The reference system used for the definition of the properties in Table 2 originates in the correspondence of the base corner between port- and aft- sides of the platform at SWL, with $\mathrm{x}$-axis pointing towards the aft-side, $\mathrm{y}$-axis pointing towards the port-side and $\mathrm{z}$-axis pointing upward.

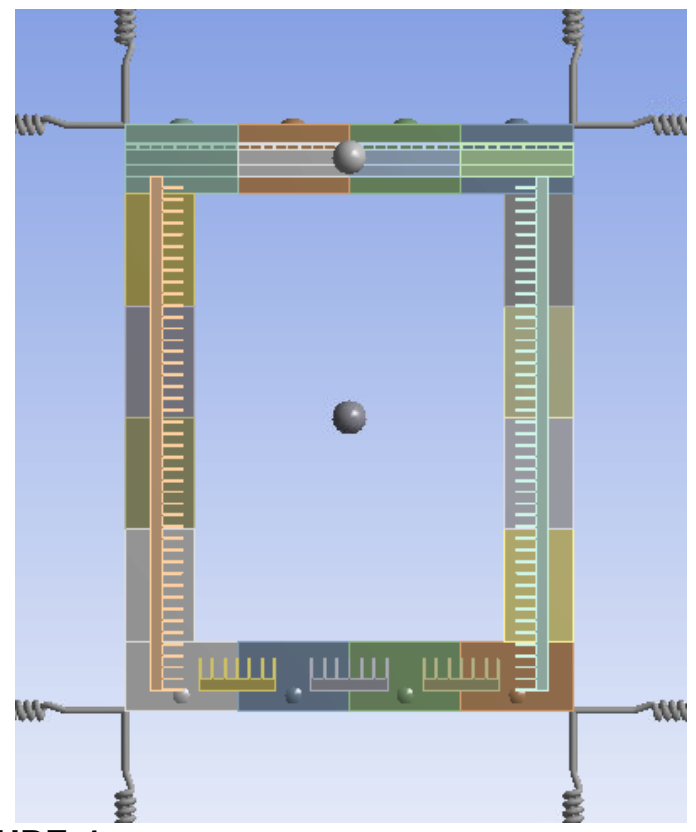

FIGURE 1: PLANAR VIEW OF THE MODEL (AFT-SIDE ABOVE) [10]. 


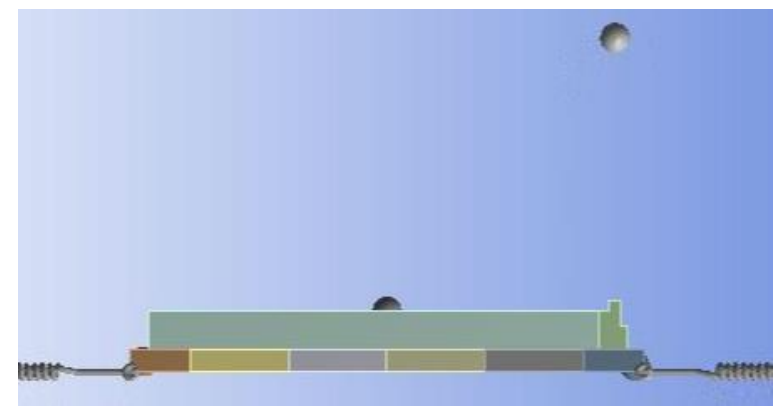

FIGURE 2: LATERAL SIDE OF THE MODEL (AFT-SIDE ON THE RIGHT) [10].

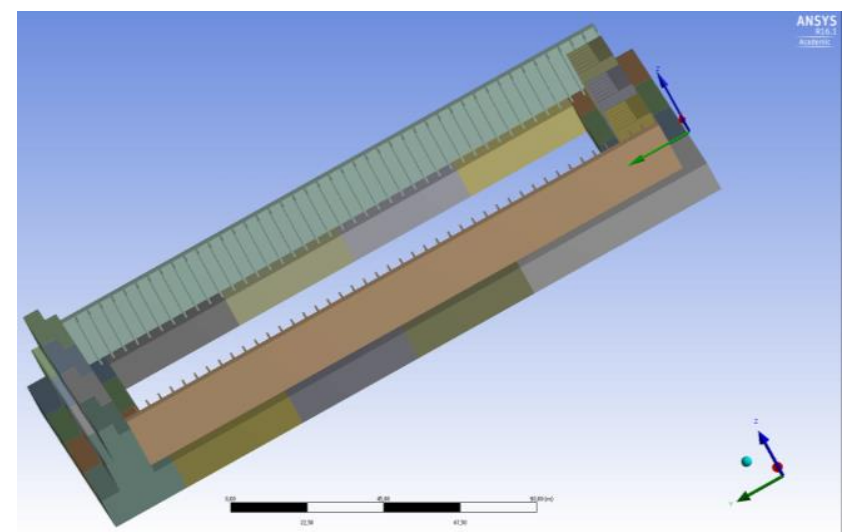

FIGURE 3: PERSPECTIVE VIEW OF THE MODEL (AFTSIDE ON THE LEFT) [10].

Table 1: Main geometric characteristics of the platform

\begin{tabular}{|c|c|c|}
\hline Properties & Units & Value \\
\hline $\begin{array}{c}\text { Aft- and fore- sides } \\
\text { length }\end{array}$ & $\mathrm{m}$ & 156.0 \\
\hline $\begin{array}{c}\text { Starboard and port-side } \\
\text { length }\end{array}$ & $\mathrm{m}$ & 204.0 \\
\hline Internal pool area & $\mathrm{m}^{2}$ & $16,848.0$ \\
\hline Draft & $\mathrm{m}$ & 20.0 \\
\hline $\begin{array}{c}\text { Max. Caisson height } \\
\text { above SWL }\end{array}$ & $\mathrm{m}$ & 8.0 \\
\hline $\begin{array}{c}\text { Base caisson width } \\
\text { (same for all caissons) }\end{array}$ & $\mathrm{m}$ & 24.0 \\
\hline $\begin{array}{c}\text { Wall caisson width } \\
\text { (excluding WEC) }\end{array}$ & $\mathrm{m}$ & 4.5 \\
\hline
\end{tabular}

Table 2: Main mass characteristics of the platform

\begin{tabular}{|c|c|c|}
\hline Properties & Units & Value \\
\hline Total mass & $\mathrm{kg}$ & $1.7310^{8}$ \\
\hline CoG position $\mathrm{x}_{\mathrm{G}}$ & $\mathrm{m}$ & 78.0 \\
\hline CoG position $\mathrm{y}_{\mathrm{G}}$ & $\mathrm{m}$ & 103.6 \\
\hline CoG position $\mathrm{z}_{\mathrm{G}}$ & $\mathrm{m}$ & -10.3 \\
\hline $\begin{array}{c}\text { Total mass moment } \\
\text { of inertia } I_{x x}\end{array}$ & $\mathrm{~kg} \mathrm{~m}^{2}$ & $9.3510^{11}$ \\
\hline Total mass moment & $\mathrm{kg} \mathrm{m}^{2}$ & $5.4810^{11}$ \\
\hline
\end{tabular}

\begin{tabular}{|c|c|c|}
\hline of inertia $I_{y y}$ & & \\
\hline $\begin{array}{c}\text { Total mass moments } \\
\text { of inertia } I_{z z}\end{array}$ & $\mathrm{~kg} \mathrm{~m}^{2}$ & $1.4110^{12}$ \\
\hline $\begin{array}{c}\text { Overall mooring } \\
\text { stiffness } K_{x x}, K_{y y}\end{array}$ & $\mathrm{~N} \mathrm{~m}^{-1}$ & $5.5010^{6}$ \\
\hline
\end{tabular}

\section{MODELLING APPROACH}

The details of the two numerical model implemented in ADINA and ANSYS are presented in this section. Firstly, the limitations and assumptions shared by both the models are briefly presented, then the peculiarity of each model is discussed in a corresponding sub-section.

\section{Assumption of the models and limitations}

Both the models implemented share some simplifying assumptions and limitations.

The wave energy converters are represented in the openchamber case, where they are not producing energy and the internal dynamics of the U-OWC does not interact with the overall dynamic behaviour of the turbine. The impact of the WECs will be assessed in further studies and is expected to be positive from a dynamic point of view, inducing the reduction of wave actions on the floating platform.

The wind turbine is regarded as a fixed body, with its own mass properties, calculated in fixed rotor conditions. Detailed dynamic studies on the given wind turbine may be found in Refs. [14]. Since the wind turbine natural frequencies are known, one of the objective of this study is to prove that they do not induce resonance with the natural properties of the structure.

The dynamics of the structure is studied in the undamped case. The structure actually features many sources of damping, including wave energy converters, aerodynamic damping of the wind turbine (see e.g. [15]), radiation damping, which has been estimated in absence of reinforcement vertical plates in the companion paper [8], viscous damping induced by the mentioned plates, the cages, etc. The impact of damping on the structure dynamics will be assessed in further studies, including also the results coming from the planned experimental activities on scaled models of the platform concept [6].

The representation of the mooring stiffness is the same for both the models. In particular, all the four springs in $\mathrm{x}$-direction have the same stiffness $K_{l}$, dimensioned so that the overall stiffness of the model matches that of Table 2, while the four springs in $y$-direction fulfil the additional requirement of providing no sway-yaw coupling, which would be induced by the slight shift of the centre of gravity in the fore-side direction in case of springs with the same stiffness. The stiffness values of each spring are reported in Table 3. It should be noted that the resulting yaw stiffness does not match that of Ref. [8]. An accurate representation of the yaw stiffness would be obtainable by using proper rotational constraints, which are not available in the 2-D model, or by shifting the springs of an appropriate arm with respect to the centre of gravity, inducing however strong alterations of the flexible modes due to the force-motion 
induced coupling in surge/sway-yaw. As a consequence, in absence of a detailed design of the mooring system, it has been chosen to represent properly only the mooring stiffness in $\mathrm{x}$ and y- directions, leaving detailed analyses on yaw stiffness and how to achieve it to the further stages of the project.

Table 3: Stiffness properties of the springs used as simplified mooring system.

\begin{tabular}{|c|c|c|}
\hline Properties & Units & Value \\
\hline $\begin{array}{c}\text { Stiffness of the four springs } \\
\text { in } x \text {-direction } K_{1}\end{array}$ & $\mathrm{~N} \mathrm{~m}^{-1}$ & $1.375 \cdot 10^{6}$ \\
\hline $\begin{array}{c}\text { Stiffness of the two springs } \\
\text { in } y \text {-direction (fore-side) } K_{2}\end{array}$ & $\mathrm{~N} \mathrm{~m}^{-1}$ & $1.353 \cdot 10^{6}$ \\
\hline $\begin{array}{c}\text { Stiffness of the two springs } \\
\text { in } y \text {-direction (aft-side) } K_{3}\end{array}$ & $\mathrm{~N} \mathrm{~m}^{-1}$ & $1.397 \cdot 10^{6}$ \\
\hline
\end{tabular}

\section{Beam model}

The beam model involves 2-node Euler-Bernoulli beam elements, where every node has 6 degrees of freedom (3 translational and 3 rotational). The hydrostatic stiffness is represented by vertical nodal springs, while the hydrodynamic added mass is represented by nodal lumped masses acting in vertical and horizontal directions; in particular, the horizontal directions are orthogonal to every side of the platform. Springs and lumped masses are obtained from hydrostatic stiffness and added mass per unit length, considering the length of the beam elements. The ballast in the fore- and aft- caissons is modelled as a distributed mass per unit length.

The beam model includes 160 elements, with a constant elastic modulus of $4.0 \cdot 10^{10} \mathrm{~Pa}$ and a mass weight of $2.5 \cdot 10^{3}$ $\mathrm{kg} \mathrm{m}^{-3}$. The main limitation of the beam model is that internal divisions and vertical stiffeners are not taken into account.

\section{D solid model}

The 3D solid model has some advantages with respect to the beam one, since it allows to represent more structure details. In particular, the internal division of the caissons and the vertical stiffeners are included in the model.

Within this model, hydrostatic stiffness been represented as a uniform elastic support, placed at the bottom of all the caissons, while hydrodynamic added mass has been represented as a set of 16 additional lumped masses correspondent to each caisson. For sake of simplicity, lumped added masses have been placed at the centre of the inverse-T section in the horizontal plane, correspondently to the quote where the section changes. Internal ballast of the fore- and aft- caissons have been represented by lumped mass elements, placed at the centre of gravity of the correspondent water ballast.

The model mesh is made up of 209,612 3D concrete elements, with a constant elastic modulus of $4.0 \cdot 10^{10} \mathrm{~Pa}$ and a mass weight of $2.5 \cdot 10^{3} \mathrm{~kg} \mathrm{~m}^{-3}$, which are the same of the former approach.

\section{RESULTS AND DISCUSSION}

The results obtained with the two codes are here presented. The first six modes identified by both the codes basically correspond to the rigid body motions of the structure, and are comparable to the results obtained using a rigid-body approach in the companion paper [8]. They are presented in the first subsection, while the other four modes correspond to the flexible motions of the structure and are presented in the second one.

\section{Rigid modes}

The natural frequencies of the six modes associated to the rigid body motions of the platform are reported in Table 4, while the corresponding mode shapes are shown in Figures 4-9.

Table 4: Natural frequencies $(\mathrm{Hz})$ of the rigid modes of the structure, as estimated by the two numerical models.

\begin{tabular}{|c|c|c|}
\hline Mode & $\begin{array}{c}\text { ADINA (beam } \\
\text { model) }\end{array}$ & $\begin{array}{c}\text { ANSYS } \\
\text { (solid model) }\end{array}$ \\
\hline 1 & 0.0232 & 0.0238 \\
\hline 2 & 0.0237 & 0.0247 \\
\hline 3 & 0.0367 & 0.0332 \\
\hline 4 & 0.0312 & 0.0361 \\
\hline 5 & 0.0435 & 0.0382 \\
\hline 6 & 0.0396 & 0.0388 \\
\hline
\end{tabular}

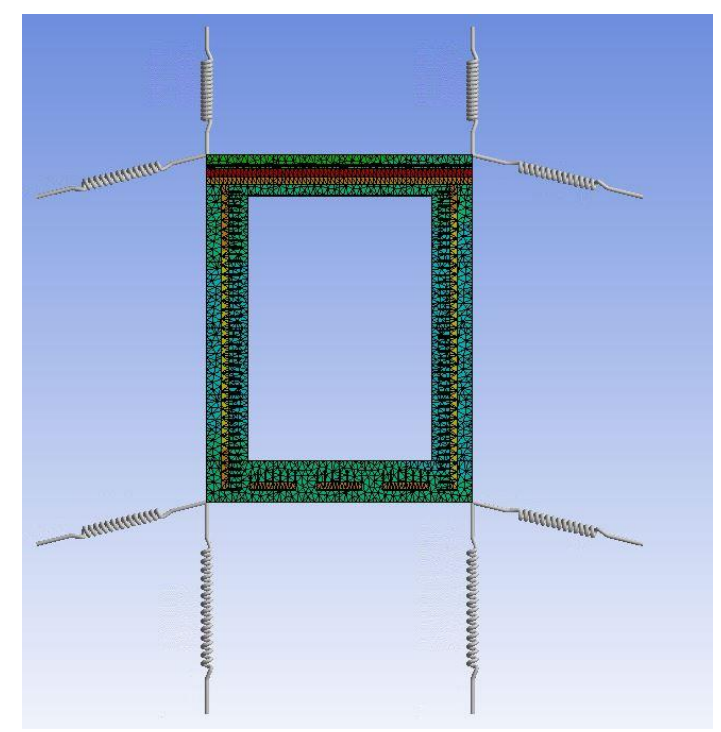

FIGURE 4: MODE SHAPE 1: ALMOST PURE SURGE [10]. 


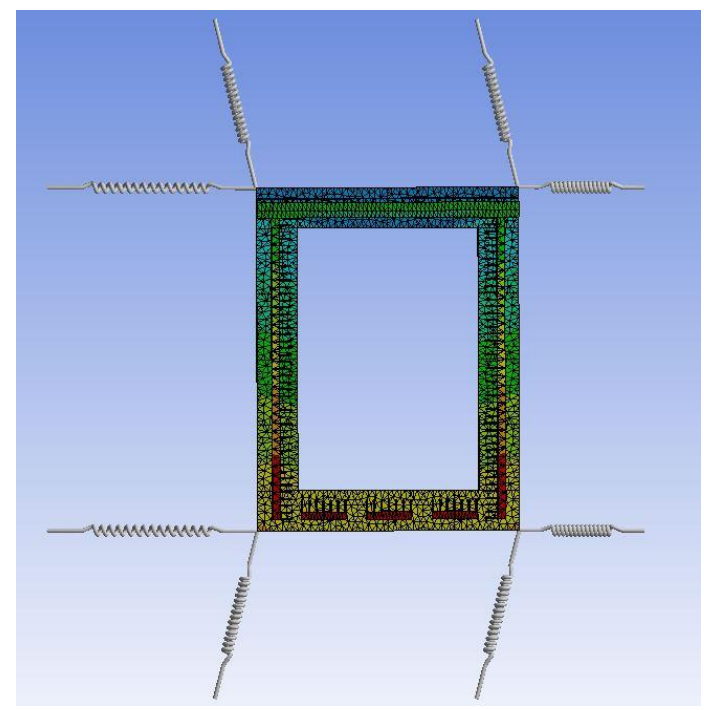

FIGURE 5: MODE SHAPE 2: ALMOST PURE SWAY [10].

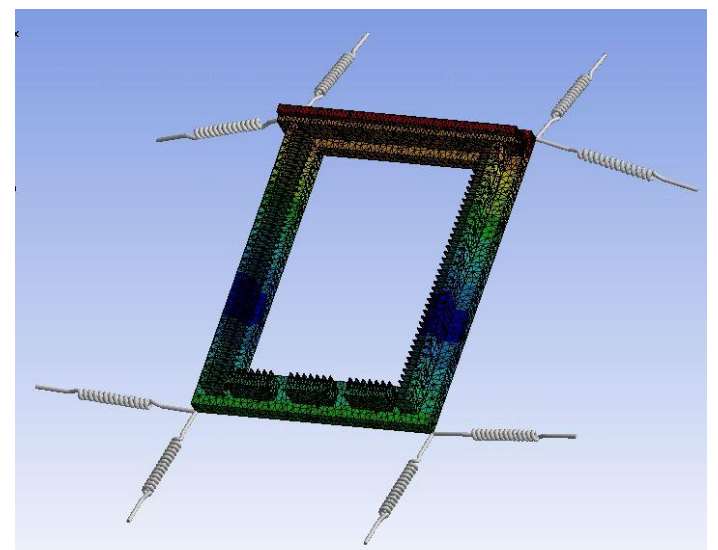

FIGURE 6: MODE SHAPE 3: ALMOST PURE PITCH [10].

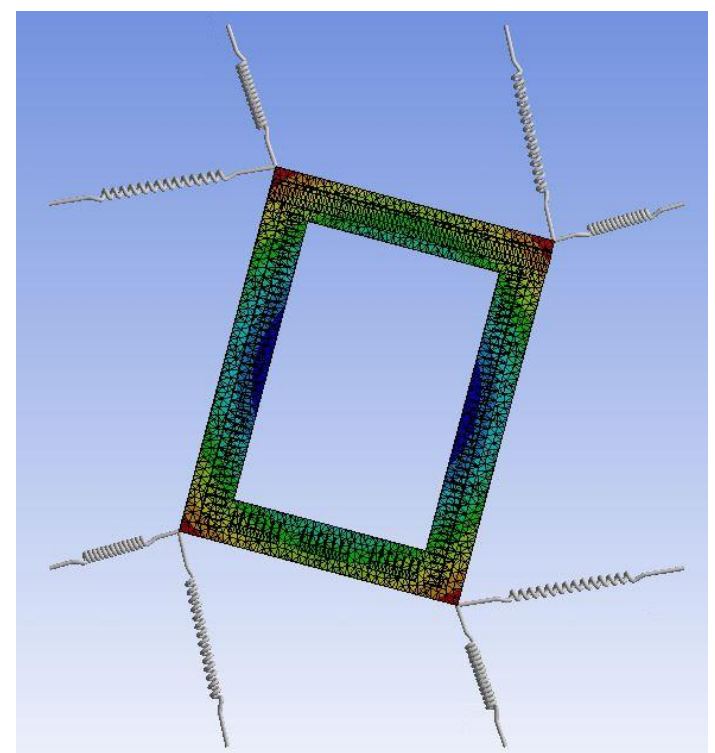

FIGURE 7: MODE SHAPE 4: ALMOST PURE YAW [10].

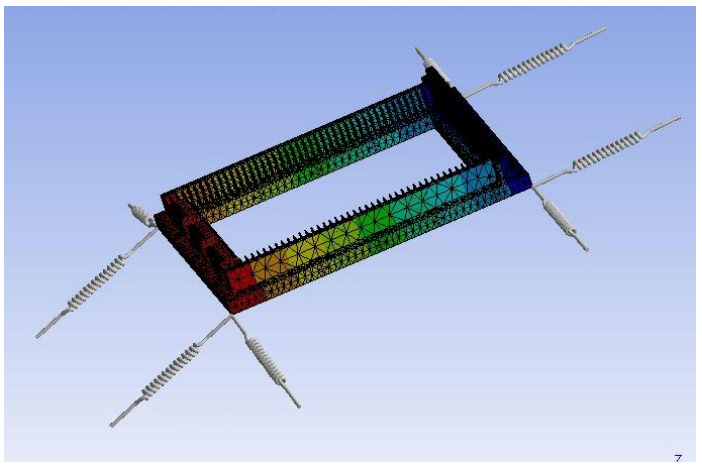

FIGURE 8: MODE SHAPE 5: ALMOST PURE COUPLING BETWEEN HEAVE AND PITCH [10].

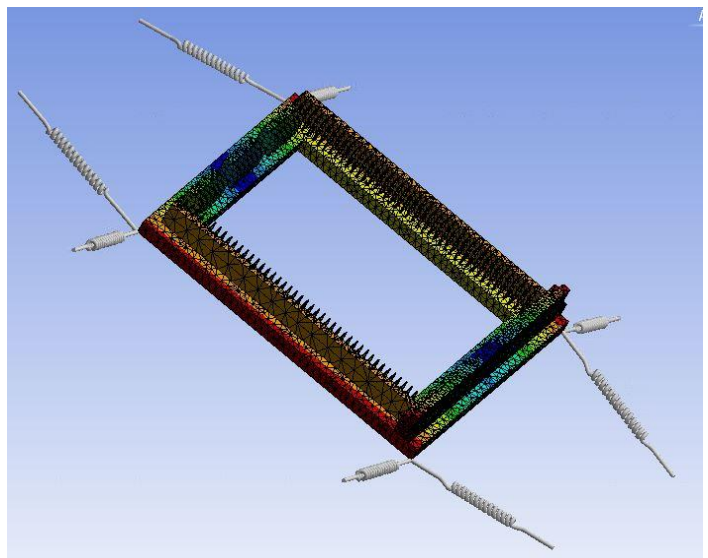

FIGURE 9: MODE SHAPE 6: ALMOST PURE ROLL [10].

The agreement between the two models is satisfying considering that mode shapes are practically identical, while frequencies are slightly different since ADINA cannot take into account the total mass and stiffness distributions as precisely as ANSYS. In particular, the beam model slightly underestimates mass and alters torsional stiffness due to the simplyfying equivalent method adopted, resulting in an alteration of the natural frequencies. For this reason, the order of the modes in Table 4, Figures 4-9 and in the following is referred to the 3D solid ANSYS model.

The first, second and fourth mode basically correspond to almost pure surge, sway and yaw motions of the platform, weakly coupled to the vertical motions and between each other. It should be noted here that, due to the important simplifications and limitations of the mooring models, the results concerning the horizontal motions must be regarded as preliminary. Further investigation about these motions and the corresponding modes will be needed after the detailed design of an opportune mooring system.

The third and sixth modes correspond to almost pure pitch and roll motions of the platform, respectively. Finally, the fifth mode represents the heave motion of the platform, which is strongly coupled with pitch.

It should be noted that the estimation of the natural frequencies are consistent with those of the RAO peak 
frequencies estimated in Ref. [8] for the six rigid body motions of the platform, however they are slightly overestimated with respect to the former approach due to the conservative method adopted for the estimation of the hydrodynamic added mass (strip theory). Again, all the frequencies are out of the range of the most important external solicitations, namely sea waves and wind turbine loads (see Fig. 10).

It is very important to note also that the mass participation factors for the first six modes in all the directions are greater than $99.9 \%$. The same occurs for the participant mass moments of inertia. This basically confirms that the structure behaves at a first approximation as a rigid body, as hypothesized in Ref. [8].

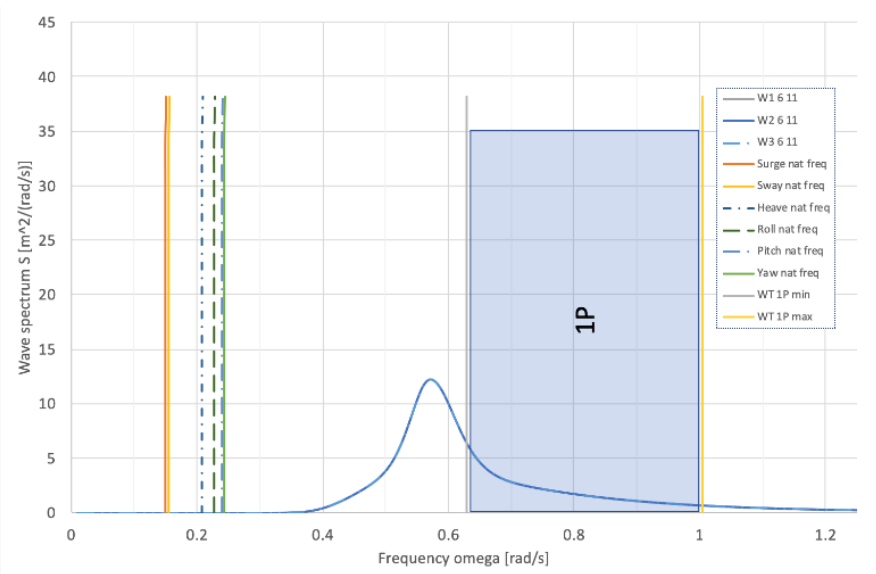

FIGURE 10: COMPARISON BETWEEN THE NATURAL FREQUENCIES OF RIGID STRUCTURAL MODES (3D SOLID MODEL) AND WAVE AND 1P INPUT LOAD FREQUENCIES.

\section{Flexible modes}

As mentioned above, rigid body motions interest almost the totality of the participant mass of the structure. Nevertheless, the first five flexible modes have been identified with the two codes, since they may play a non-negligible role in structure dynamics, depending on their natural frequency, expecially in terms of fatigue and particular load conditions.

The natural frequencies of these five modes are reported in Table 5, while the corresponding mode shapes are shown in Figures 11-15.

Table 5: Natural frequencies $(\mathrm{Hz})$ of the flexible modes of the structure, as estimated by the two numerical models.

\begin{tabular}{|c|c|c|}
\hline Mode & $\begin{array}{c}\text { ADINA } \\
\text { (beam model) }\end{array}$ & $\begin{array}{c}\text { ANSYS } \\
\text { (solid model) }\end{array}$ \\
\hline 7 & 0.2622 & 0.2692 \\
\hline 8 & 0.6785 & 0.5650 \\
\hline 9 & 0.6750 & 0.7254 \\
\hline 10 & N. D. & 0.7831 \\
\hline 11 & 0.9706 & 0.9680 \\
\hline
\end{tabular}

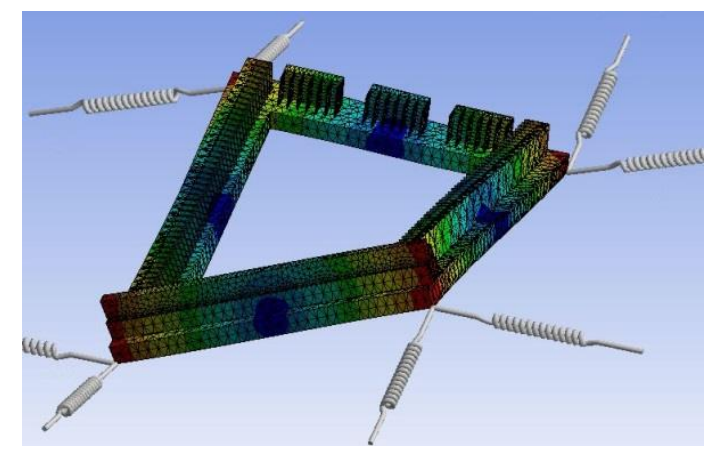

FIGURE 11: MODE SHAPE 7 [10].

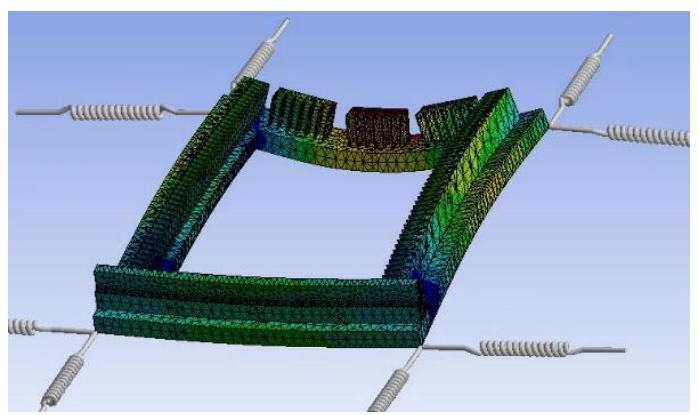

FIGURE 12: MODE SHAPE 8 [10].

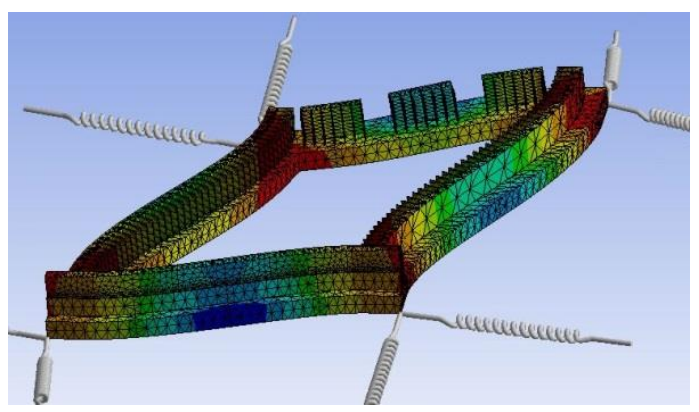

FIGURE 13: MODE SHAPE 9 [10].

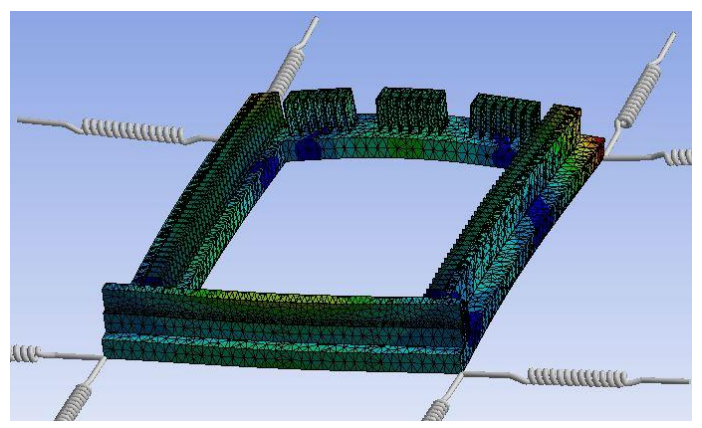

FIGURE 14: MODE SHAPE 10 [10] (NOT DETECTED BY BEAM MODEL). 


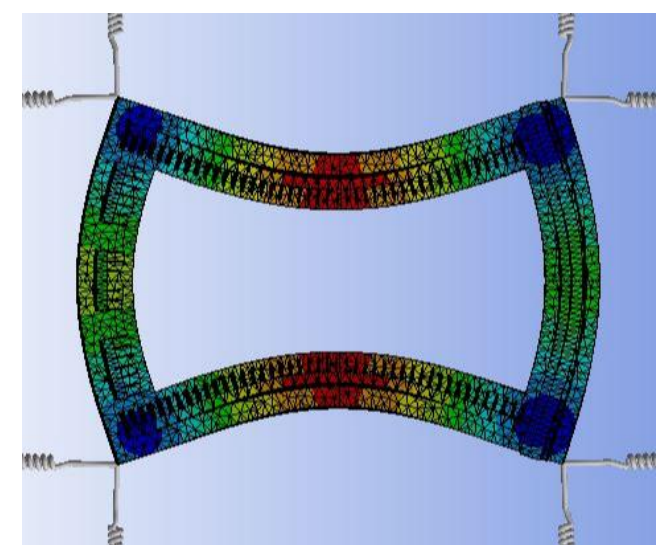

FIGURE 15: MODE SHAPE 11 [10].

It is interesting to note that the beam model catches the first three modes and the fifth one, but misses the fourth due to its intrinsic limitation with respect to the representation of the structure sides as 3D beams.

As in the previous case, the agreement between the two models is very good in terms of mode shapes, except for the fourth mode as previously mentioned, while natural frequencies are slightly different between each other due to the unavoidable differences in terms of mass and stiffness distribution.

It is also very important to note that again all frequencies are outside the ranges of danger for the structure (See Fig. 16).

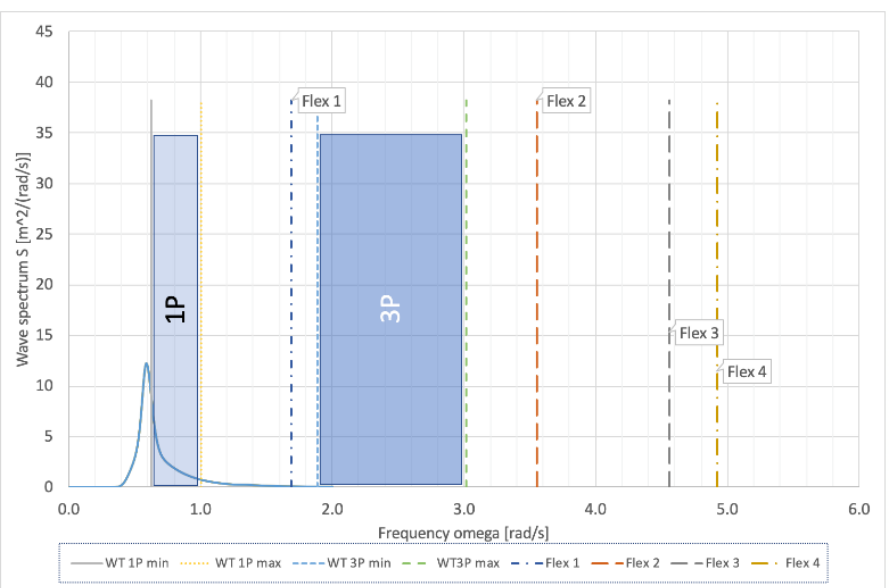

FIGURE 15: COMPARISON BETWEEN THE NATURAL FREQUENCIES OF FLEXIBLE STRUCTURAL MODES (3D SOLID MODEL) AND WAVE, 1P AND 3P INPUT LOAD FREQUENCIES.

\section{CONCLUSIONS}

A novel concept for large multi-purpose floating structures is presented within the context of the "Blue Growth Farm" project, funded by the EU. The concept is based on a rectangular-shaped concrete platform, equipped with aquaculture facilities, wave and wind energy converters, and relevant ancillary systems.

In this paper, a preliminary undamped modal analysis of the structure is carried out, using a beam and a $3 \mathrm{D}$ solid numerical model. Both the models are used to identify natural frequency, mode shape and mass participation factor of the first eleven modes of the structure. In the companion paper [8], rigid-body dynamic response analyses are conducted, adopting a potential code able to capture diffraction.

The results obtained here substantially confirm the rigid body dynamics hypothesis, since the cumulative participant mass to the rigid modes is greater than $99 \%$ of the total mass, and the same occurs to the participant mass moments of inertia. In addition, the advantages and limitations of the beam model with respect to the $3 \mathrm{D}$ one are highlighted. On one side, the beam model is able to represent with an acceptable accuracy the most important dynamic characteristics of the structure. On the other side, the simplification introduced (beams with uniform section, simplified representation of the stiffeners, etc.) introduce some sources of imprecision in terms of mass and stiffness distribution, which result in a non-negligible alteration of the natural frequencies estimated and in the failure of the identification of the tenth structural mode.

Finally and foremost, the present study confirms that the natural frequencies of the most relevant structure modes are relatively far from those of the most important solicitations (i.e. wave and wind turbine), which encourages further analysis on optimized versions of the structure concept proposed.

\section{Future work}

The present analysis is intended as a preliminary study on a novel structure concept, hence it inherently suffers from simplifications and limitations, which will be progressively reduced in the further stages of the "Blue Growth Farm" project.

In order to achieve a final confirmation about the concept feasibility, structural analyses will be carried out, based on the modal analysis here presented and on the load definition, achieved in the companion paper [8]. In addition, further hydrodynamic numerical analyses will be performed to assess the attenuation of the wave motion in the internal pool, and its dependence on the structure motions, which is a crucial topic for aquaculture purposes.

Then, the numerical models will be refined by including wind and wave energy converter dynamics, and validated through small- and intermediate- scale physical experimental activities [6], which will be, respectively, carried out at the ECN ocean basin [16] and at the Natural Ocean Engineering Laboratory of Reggio Calabria [17], respectively. In particular, experimental activities will be crucial for the estimation of damping, which is neglected in the present study.

\section{ACKNOWLEDGMENTS}

This work has been produced in the framework of the Blue Growth Farm project (http://www.thebluegrowthfarm.eu/), which has received funding from the European Union's Horizon 2020 research and innovation programme under Grant Agreement number 774426. The content of the work does not report the opinion of the European Commission and reflects only the views of the author(s), including errors or 
omissions. The European Commission is also not liable for any use that may be made of the information contained herein.

\section{REFERENCES}

[1] C. Ruzzo, V. Fiamma, M. Collu, G. Failla, V. Nava, F. Arena (2018) On intermediate-scale open-sea experiments on floating offshore structures: Feasibility and application on a spar support for offshore wind turbines. Marine Structures 61: 220-237. DOI: 10.1016/j.marstruc.2018.06.002.

[2] C. Ruzzo, V. Fiamma, V. Nava, M. Collu, G. Failla, F. Arena (2016) Progress on the experimental set-up for the testing of a floating offshore wind turbine scaled model in a field site. Wind Engineering 40(5): 455-467. DOI: 10.1177/0309524X16660023.

[3] G. Failla, F. Arena (2015) New perspectives in offshore wind energy. Philosophical Transactions of the Royal Society A 373: 20140228. DOI: 10.1098/rsta.2014.0228.

[4] C.M. Wang, Z.Y. Tay, (2011) Very large floating structures: applications, research and development. Procedia Engineering 14:62-72. DOI: 10.1016/j.proeng.2011.07.007

[5] M. Lamas-Pardo, G. Iglesias, L. Carral (2015) A review of very large floating structures (VLFS) for coastal and offshore uses. Ocean Engineering 109:677-690. DOI: 10.1016/j.oceaneng.2015.09.012

[6] The Blue Growth Farm Project website. http://www.thebluegrowthfarm.eu/ (Accessed 3 January 2019)

[7] F. Lagasco, F. Vassalli, R. Pennino, G. Gentile, L. Fiacco, G. Urbano, P. Corvaglia, C. Idri (2019) New engineering approach for the development and demonstration of a multi-purpose platform for the blue growth economy. International Conference on Offshore Mechanics and Arctic Engineering - OMAE2019-96104, Glasgow, UK.

[8] L. Li, A. K. Abhinav, M. Collu, C. Ruzzo, F. Arena, (2019). Analysis of the Coupled Dynamics of an Offshore Floating Multi-Purpose Platform, Part A: Rigid-Body Analysis. International Conference on Offshore Mechanics and Arctic Engineering - OMAE2019-96212, Glasgow, UK.

[9] ADINA, Version 9.3, ADINA R. \& D. Inc., Watertown, 2017.

[10] ANSYS $®$, Academic research, release v.16.1.

[11]G. Malara, A. Romolo, V. Fiamma, F. Arena, On the modelling of water column oscillations in U-OWC energy harvesters, Renewable Energy 101 (2017) 964-72.

[12] F. Arena, A. Romolo, G. Malara, V. Fiamma, V. Laface, (2017) The first full operative U-OWc plants in the port of Civitavecchia. Proceedings of the International Conference on Offshore Mechanics and Arctic Engineering OMAE2017, Trondheim, Norway

[13] C. Bak, F. Zahle, R. Bitsche, T. Kim, A. Yde, L.C. Henriksen, M.H Hansen, J.P.A.A. Blasques, M. Gaunaa, A.
Natarajan, (2013) The DTU 10-MW reference wind turbine. In: Danish Wind Power Research 2013.

[14] Fontanella A., Taruffi F., Muggiasca S., Belloli M., (2019) Design methodology for a floating offshore wind turbine large-scale outdoor prototype. International Conference on Offshore Mechanics and Arctic Engineering - OMAE2019, Glasgow, UK.

[15] H. Bredmose, F. Lemmer, M. Borg, A. Pegalajar-Jurado, R.F. Mikkelsen, T.S. Larsen, T. Fjelstrup, W. Yu, A.K. Lomholt, L. Boehm, J.A. Armendariz, (2017) The Triple Spar campaign: Model tests of a 10MW floating wind turbine with waves, wind and pitch control. Energy procedia, 137: 58-76.

[16] Ecole Centrale de Nantes, Ocean Test Facilities. Website: https://www.ec-nantes.fr/research-facilities/ocean-testfacilities/ocean-test-facilities-182847.kjsp (Accessed 3 January 2019)

[17] Natural Ocean Engineering Laboratory of Reggio Calabria website http://noel.unirc.it/ (Accessed 3 January 2019) 